\title{
My experience from CVUT
}

\author{
Sigbjørn Herstad \\ Department of Geomatics ${ }^{1}$ \\ Faculty of Engineering Science \& Technology ${ }^{2}$, Norwegian University of Technology and \\ Science $^{3}$ \\ E-mail: sigbjohe@stud.ntnu.no
}

\section{Introduction}

Through this paper I will try to describe both my background and my study- period in Prague. If you have further questions or want to know more, don't hesitate to contact me.

\section{Master of Science in Engineering and ICT (Information \& Communication Technology)}

\section{Background}

This branch was created because there are a lot of good engineers in all the engineering branches (not only geomatics) and also people who can handle information technology. However it is not always the reality that a good engineer can handle information technology equally well, and vice versa. Therefore there was a need for people who where skilled in both engineering and information technology. This happened in 2002, the same year I started studying at the university.

\section{Structure of the field of study}

Master of Science in Engineering and ICT (Information \& Communication Technology) is a 5 years Master program. The first 2 years includes basic engineer and computer- courses (mathematics, object- oriented programming, physics, mechanics, databases, fluid-mechanics, statistics, algorithms and computer structures etc.) After the first two years a choice has to be made in which direction you want to go. There is limited number of places on each branch. These are the study- branches possible to choose between: These are the study- branches possible to choose between:

1. Energi- og prosessteknikk ${ }^{4}$ [Norwegian], Energy \& Process Engineering ${ }^{5}$ [English]

2. Geofag og petroleumsteknologi ${ }^{6}$ [Norwegian], Petroleum Engineering ${ }^{7}$ [English]

\footnotetext{
${ }^{1}$ http://www.geomatikk.ntnu.no/english/index.html

${ }^{2}$ http://www.ivt.ntnu.no/e_index.php

${ }^{3}$ http://www.ntnu.no/

${ }^{4}$ http: //www. studier.ntnu.no/rw_index_sprog.php?dokid=40b4970b08f 821.74711920

${ }^{5}$ http://www.ept.ntnu.no/en/

${ }^{6}$ http: //www. studier.ntnu.no/rw_index_sprog.php?dokid=3fe15ace7dbcd1. 58219460

${ }^{7}$ http://www.ipt.ntnu.no/
} 
3. Geomatikk ${ }^{8}$ [Norwegian], Geomatics ${ }^{9}$ [English]

4. Konstruksjonsteknikk ${ }^{10}$ [Norwegian], Structural Engineering ${ }^{11}$ [English]

5. Marin teknikk ${ }^{12}$ [Norwegian], Marine Civil Engineering ${ }^{13}$ [English]

6. Produktutvikling og materialer ${ }^{14}$ [Norwegian], Product Development $\&$ Materials $^{15}$ [English]

During the 4th or 5th year you have to decide further in which specialization you want to go. For instance in Geomatics you can choose between:

- Cartography and geographic information sciences ${ }^{16}$

- Geodesy $^{17}$

- Photogrammetry and remote sensing ${ }^{18}$

For a short introduction to Master of Science in Engineering and the different fields it is possible to study I recommend to visit Hybrida ${ }^{19}$ (a union for the students who study Master of Science in Engineering) and look at the $P D F-f i l e^{20}$. For the moment it is only in Norwegian, but it contains alot of pictures and is therefore easily understandable.

\section{Experience from studying at NUTS (Norwegian University of Technology and Science) in Trondheim}

The study- branch was founded the year I started at the university. Since it was the first year, everything was new. Most of the courses and the program for the first 3 years was planned. However there have been changes in courses and which year they should be mandatory.

I considered applying for the information technology study- branch, but I was afraid that this was only focused on computers and too much technical. I wanted something in between. For me it was very positive to delay the decision about which direction to go for 2 years. With this line everyone have the same courses the 2 first years. This result in 2 more years to decide in which field you really want to study.

\footnotetext{
${ }^{8}$ http: //www. studier.ntnu.no/rw_index_sprog.php?dokid=405868776327e8. 28972588

${ }^{9}$ http://www.geomatikk.ntnu.no/english/index.html

${ }^{10}$ http: //www. studier.ntnu.no/rw_index_sprog.php?dokid=40b49aa561daa2 .96785114

${ }^{11}$ http://www . bygg.ntnu.no/ktek/

${ }^{12}$ http://www. studier.ntnu.no/rw_index_sprog.php?dokid=40b498480b55c1. 16452366

${ }^{13} \mathrm{http}: / /$ www.ivt.ntnu.no/bat/english/mb_english/

${ }^{14}$ http: //www . studier.ntnu .no/rw_index_sprog.php?dokid=421259891e9108.53831450

${ }^{15}$ http://www.immtek.ntnu.no/engelsk/

${ }^{16}$ http://www.geomatikk.ntnu.no/english/Intro/cartography.html

${ }^{17}$ http://www.geomatikk.ntnu.no/english/Intro/geodesy.html

${ }^{18}$ http://www.geomatikk.ntnu.no/english/Intro/photogrammetry.html

${ }^{19}$ http://www .hybrida.ntnu.no/hybridaweb/Skole/

${ }^{20}$ http://www .hybrida.ntnu.no/filer/IIKT_IVTstyret050204.pdf
} 


\section{Experience from studying at CVUT (Czech Technical University) in Prague}

I was recommended to go to Germany or Finland because these are countries that have well known universities within geomatics. However I decided to choose to go a different road. I wanted to study somewhere exotic (not in the Australian beach-and-surfing-way) and different from Norway. I found out that at CVUT it would be possible to study my 4th year. I knew it may be difficult to find the subjects needed, but hoped it would be possible to take more computer- courses and other courses. That was also one of my intentions to go abroad finding new courses which I normally would not have discovered.

\section{Negative experiences}

- Registration for courses. It took some time to find people, departments and the right places to queue for different papers.

- Not integrating with Czech students. Since most of the English- courses are made for ERASMUS and foreign students there are few or no Czech people attending them. Integration between Czech and foreign students would become easier if it was a better mix between Czech and foreign students in classes.

- Too many courses. It is obligatory to have 30 ECTS credits each semester in Norway. Most of the courses in Norway have 7,5 ECTS - so 4 courses each semester is common the first years. While at CVUT I needed 10 courses to get the same amount of ECTS.

- Courses are full or cancelled. Many of the courses which where planned opened when applying for a year at CVUT were closed. The most popular courses where crowded very early, and therefore difficult to register.

- Computer rooms and places to study. There seems to be too few computers and places to study. However it doesn't seem to be a problem for the foreign students, because most of them have their own computer at the dormitory.

\section{Positive experiences}

- Select courses from different faculties. The possibility to select courses from all the different faculties is an advantage.

- International office is helpful. Without the international office I think it would be even more chaotic to find out where to go and how to register, so a big thank to them for helping new students find their place.

- International Student Club ${ }^{21}$ - important for the social life of the students. Active not only during the first weeks, but they arrange trips throughout the whole year.

- Helpful teachers. Most of the teachers are very helpful and want to help as much as possible. Even though a lot of the teachers are very busy, most of them takes time and shows interest in helping foreign students.

${ }^{21}$ http: //www . isc . cvut.cz/en/index . php?menu=1 
- More interesting courses. Since it is possible to combine courses from different faculties there are a wide variety of different courses to select between.

- Different locations. The faculties are spread all around Prague, from Dejvicka and Karlovo Namesti to Florenc. Since I had courses in 3 faculties I had to travel between these locations. First I thought it would be a problem, but it made it easier to explore the city.

- Meeting other international students. Perhaps one of the main reasons why I took a year abroad. Easy to get in touch with international students.

- New contacts and relations for more studies/work abroad.

- Traveling. It is easy to travel around in the Czech Republic and the nearby countries. It is possible to take a week off and travel.

\section{Suggestions and ideas for further consideration}

I will try to make some suggestions on how to improve the conditions to get more people to study the branch of geomatics at CVUT. It was mostly luck that made me discover CVUT and the fact that it was possible to study here. Increased cooperation abroad with other universities would be good, both in exchanging students for 1 or 2 semesters, but also perhaps cooperation in courses. For instance 2-3 people from different universities cooperate through the semester (through internet) and present a final project. More accurate information on the homepage would be good. There is a list of subjects, but will all of them be open? Is it possible to have more project- oriented courses?

It is difficult (but possible) for foreign students to attend Czech lessons and courses. I think it is easier for Czech people to take part in English lessons than the opposite. For those of the Czech students going abroad to study for a period of time it is also and advantage to already have had some courses in English. So perhaps some of the Czech- courses can be taught in English? 